\title{
Impact of base station antenna height and antenna tilt on performance of LTE systems
}

\author{
Jolly Parikh ${ }^{1}$, Anuradha Basu ${ }^{2}$ \\ ${ }^{I}$ Ph.D scholar at Mewar University, Asst. Prof., ECE, Bharati Vidyapeeth's College of Engg., Delhi, India \\ ${ }^{2}$ Head of Department, ECE, Bharati Vidyapeeth's College of Engg., Delhi, India
}

\begin{abstract}
The impact of base station antenna height and antenna tilt on SINR in LTE systems have been discussed in this paper. Vienna LTE system level simulator has been used to obtain the results for studying the performance of LTE systems. Results highlight the point that changes in antenna height and tilt angle results in variations in the signal coverage and path loss of the network which in turn varies the SINR of the overall system and thereby the quality of service of the network.
\end{abstract}

Keywords: Antenna height, antenna tilt, macroscopic fading, LTE systems, SINR.

\section{Introduction}

LTE systems encounter heavy interference at the cell edges due to the usage of a frequency reuse ratio of 1 . The issue of interference management can be handled by carrying out precise parameterization while planning and deploying the network. Care should be taken to ensure that there is maximum signal strength of the received signal and minimum interference from neighboring cell in the region of interest. Antenna height and antenna tilt are two of the few parameters considered for optimization of the network performance. Both are independent of each other and can be independently varied for performance enhancement of the network.

\section{Effect of antenna height}

Antenna height plays an important role in determining the coverage of a base station in a cellular system. Mathematical representation of various path loss prediction models indicate that base station antenna height is one of the important parameter for calculation of path losses in a channel exhibiting different environmental conditions. The flat earth path loss is given as,

$$
\mathrm{L}=\mathrm{d}^{4} /\left(\mathrm{h}_{\mathrm{t}}^{2} * \mathrm{~h}_{\mathrm{r}}^{2)}\right.
$$

Where, $\mathrm{L}=$ path loss, $\mathrm{h}_{\mathrm{t}}=$ transmitter antenna height, $\mathrm{h}_{\mathrm{r}}=$ receiving antenna height, $\mathrm{d}=$ distance between transmitter and receiver. From the path loss equation it can be seen that path loss is dependent upon height of the transmitting and receiving antenna. Theoretically, considering antenna height the path loss drops off as $1 / \mathrm{d}^{4}$. Practically it has been observed that an increase or decrease in antenna height results in increase or decrease of the signal coverage depending on the location and surroundings of the base station. Previous studies have reported the impact of antenna height on delay spread [1-5] and coverage [6]. This paper discusses the impact of antenna height on SINR and macroscopic fading.

\section{Effect of antenna TILT}

Antenna tilt (inclination or angle of the antenna to its axis) of base stations in wireless network is a key factor for determining the cell coverage. Mechanically or Electrically down tilting the elevation beam of an antenna directs the null points of the antenna pattern towards the horizontal plane thereby preventing the energy from propagating into neighboring cells. In systems with small cell size (where the distance between the cell centre and the cell edge is very less), electrical tilting proves to be a cost effective and trivial solution to the interference problems. While mechanical tilt provides reduced coverage in the central direction and more coverage in side directions, pattern blooming [7], the vertical tilt results in uniform modification in the antenna radiation pattern (i.e. antenna gain on the horizon decreases). Fig. 1 shows the coverage predictions for 3 types of tilting conditions. 

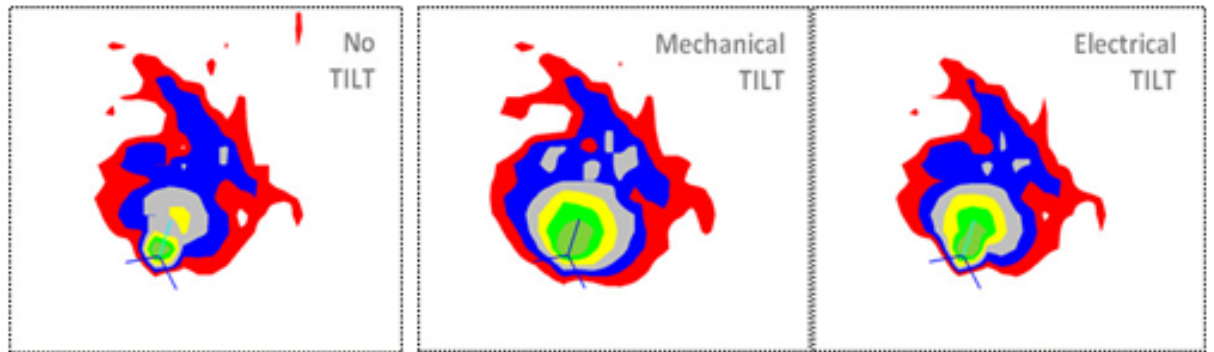

Figure 1: Coverage predictions for different antenna tilt conditions

Over a period of time much research work has been carried out discussing the various applications of antenna tilting for improving the performance of the different networks. In [8] GSM system performance improvement with antenna tilting has been discussed. In [9] and [10,11] focus is on UMTS and LTE system performances respectively, with regard to antenna tilting. Tilting plays a crucial role in interference management [12], improves the conditions for handover by minimizing unwanted overlapping with neighboring cells [13]. With tilting, interference at cell boundary can be removed and the received signal strength in region of interest (ROI) can be increased along with minimal interference to neighboring cells [14]. Traffic capacity of a cell relates to the antenna tilt angles. In [15] J. Niemela and et. al. have shown how high throughput can be achieved with a 6 degree and 14 degree vertical tilt angles for cell centered traffic and cell edge traffic respectively.

\section{Simulation Results}

Simulations were carried out using the Vienna LTE system level simulator [16]. Table 1 represents the system parameters used for the present study. A seven cell reuse system, with 3 sectors/cell, has been used considering an urban scenario where inter eNodeB distances are $500 \mathrm{~m}$.

Table 1: System parameters

\begin{tabular}{|l|c|}
\hline Parameter & Values \\
\hline Bandwidth & $20 \mathrm{MHz}$ \\
\hline Carrier frequency & $2.14 \mathrm{GHz}$ \\
\hline Simulation Time & $25 \mathrm{TTI}$ \\
\hline Inter eNodeB distance & $500 \mathrm{~m}$ (urban) \\
\hline Minimum Coupling Loss & $70 \mathrm{~dB}($ urban) \\
\hline Pathloss Models & urban (TS36942) \\
\hline Max eNodeB Tx power & $15,20,25 \mathrm{dBi}$ \\
\hline Max antenna gain & $25 \mathrm{~m}, 30 \mathrm{~m}, 35 \mathrm{~m}$ \\
\hline Antenna Height & $0,1,2 \mathrm{deg}$ \\
\hline Antenna Tilt(electrical) & $9 \mathrm{~dB}$ \\
\hline UE Noise Figure & $-174 \mathrm{dBm} / \mathrm{Hz}$ \\
\hline UE Thermal Noise Density & 10 \\
\hline UEs per eNodeB & $5 / 3.6 \mathrm{~m} / \mathrm{s}$ \\
\hline UE speed & \\
\hline
\end{tabular}

The Fig. 2 (a,b,c) shows the plots for ROI SINR CDF for three different antenna heights of $25 \mathrm{~m}, 30 \mathrm{~m}$ and $35 \mathrm{~m}$ respectively. From the plots it can be seen that as the antenna height increases from $25 \mathrm{~m}$ to $35 \mathrm{~m}$, for a given SINR (e.g. SINR of $5 \mathrm{~dB}$ ), the distribution of SINR varies from low to high. It is lower for antenna height of $25 \mathrm{~m}$ as compared to that for the antenna heights of $30 \mathrm{~m}$ and $35 \mathrm{~m}$. Thus the SINR of the system is higher in case of antenna heights of $25 \mathrm{~m}$ and it decreases as the height increases. This is because with increase in antenna height in urban areas the coverage at the cell edges increases due to which inter cell interference increases. Also, the signal strength in the areas adjacent to the base station would become poor which results in poor quality of service in these areas. The overall SINR of the system decreases. 


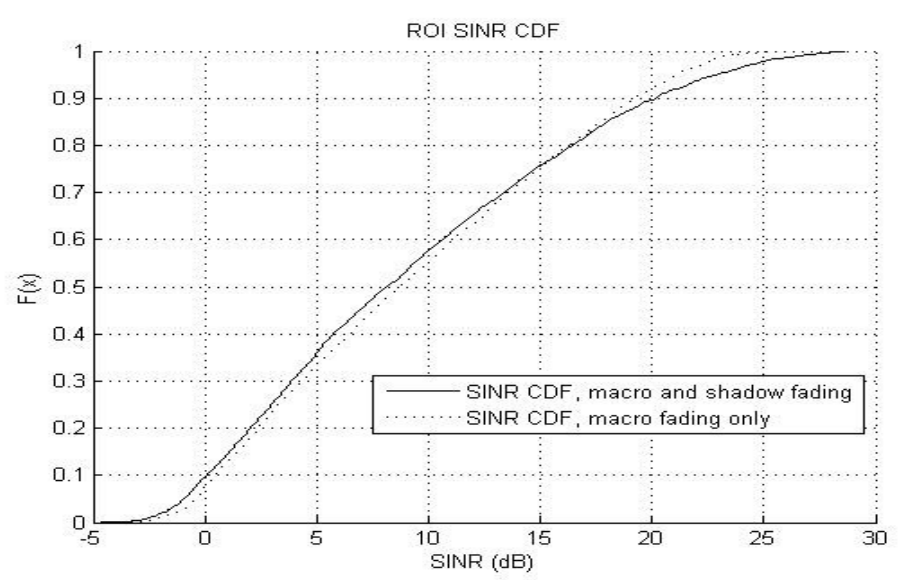

(a)

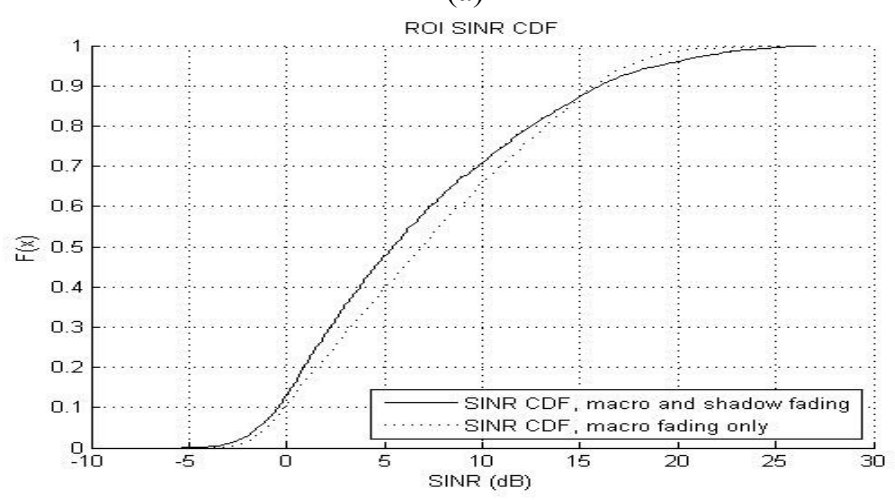

(b)

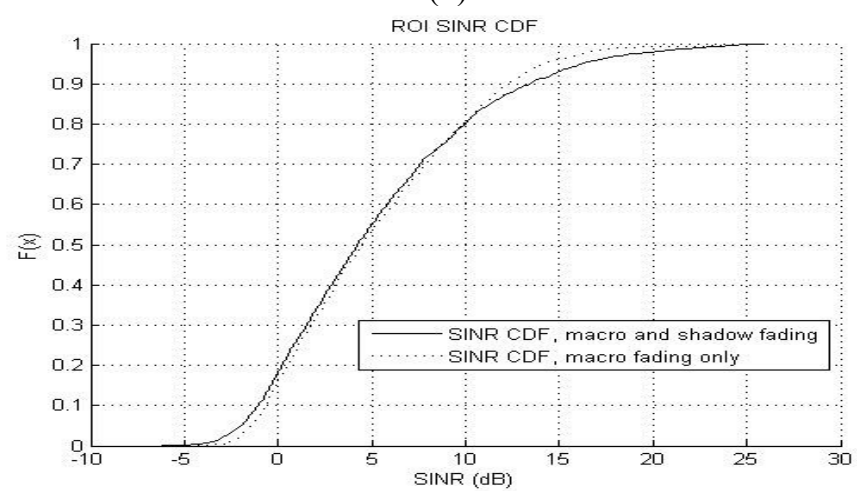

(c)

Figure 2: Region of interest SINR CDF plots for antenna heitghts (a) 25mts (b) $30 \mathrm{mts}$ (c) $35 \mathrm{mts}$.

Practically, once the antenna of certain height has been deployed it is difficult to change its height as this involves replacement of new antenna with antenna of modified heights. Also the coverage of traffic load, interference management and other such planning issues need to be redefined and this increases the cost for the network providers. Hence, until and unless there is no other option available except to change the antenna height, providers would prefer to consider making changes in the other optimization parameters of planning. Antenna tilt angle is one of these parameters generally preferred.

The Fig. 3 shows the macroscopic fading occurring in the target sector for 3 different antenna heights. It is seen that the red color area (denoting higher signal strength i.e high SINR) near the base station, decreases as the base station antenna height is increased and after a certain height value it diminishes completely. This denotes that user equipments in the areas adjacent to the base station experience high SINR. 

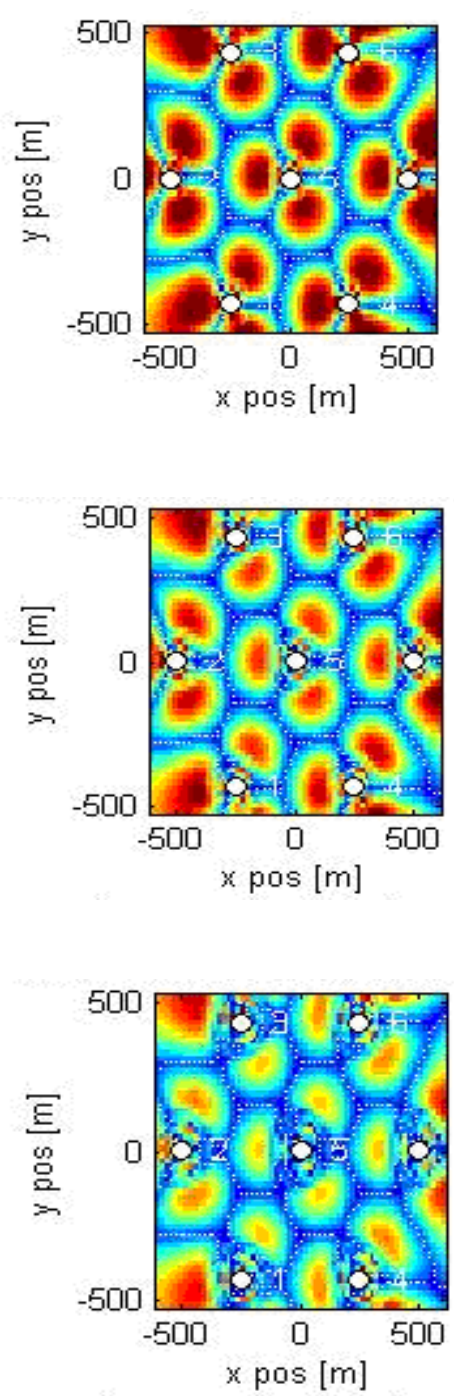

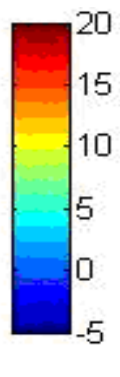

(a)
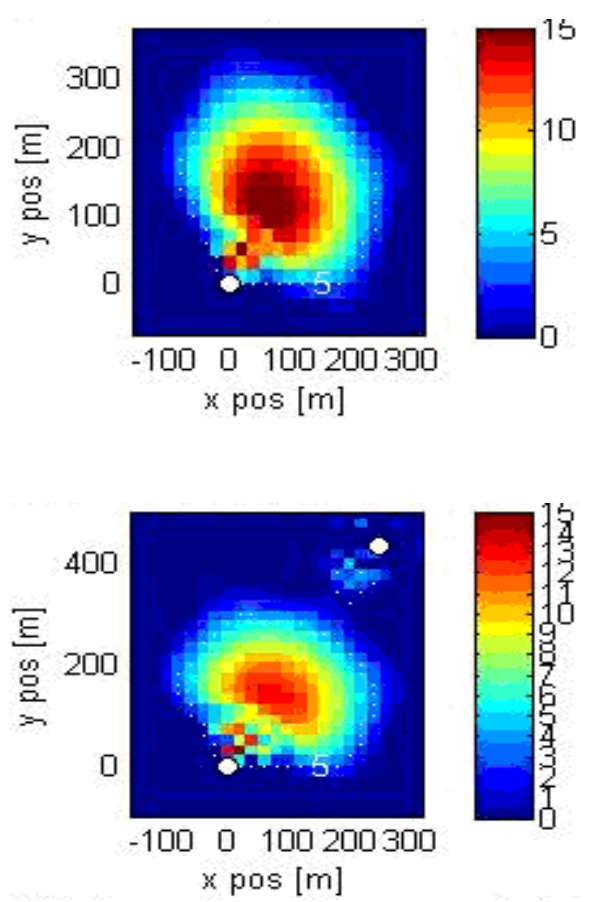

(b)
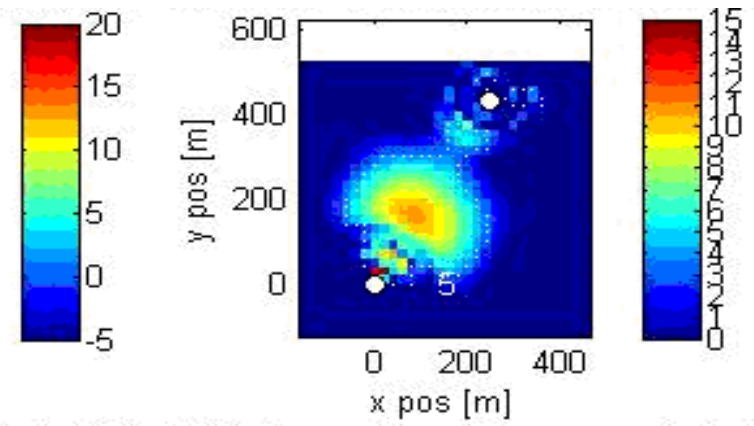

(c)

Figure 3: Macroscopic fading for antenna heights of (a) $25 \mathrm{mts}$ (b) $30 \mathrm{mts}$ (c) $35 \mathrm{mts}$

This is because with lower antenna heights at the base station, the signals stay confined to areas near to the base station as the coverage is less. As antenna height is increased, low signal coverage increases to the cell edges. From Fig. 3(a) and 3(b) it is seen that blue color region (denoting poor signal strength) spreads out and reaches the adjacent cell base station area and this results in interference. Thus SINR of the system decreases. Thus care should be taken to ensure that base station antenna height does not exceed to a value where resulting interference becomes uncontrollable such that SINR of the system degrades drastically.

For the given scenario it can be seen that in urban areas an antenna height of $25 \mathrm{~m}$ provides better SINR as compared to antenna height of $35 \mathrm{~m}$. Whereas in suburban and rural areas larger antenna heights will provide better performance, as here the inter site distances are larger so interference from neighboring base station will be less. Practically, antenna heights of $50 \mathrm{~m}$ for suburban areas and $80 \mathrm{~m}$ for rural areas have been defined in LTE encyclopedia.

One of the solutions, to avoid frequent changes in antenna height (e.g. to compensate for the obstructions from newly constructed tall buildings etc) and interference problem at cell edges (due to decrease in cell size because of introduction of new cells for supporting higher traffic load), is the tilting of the antenna. Fig. 4 shows the effect of electrical tilting of an antenna on the macroscopic fading. 

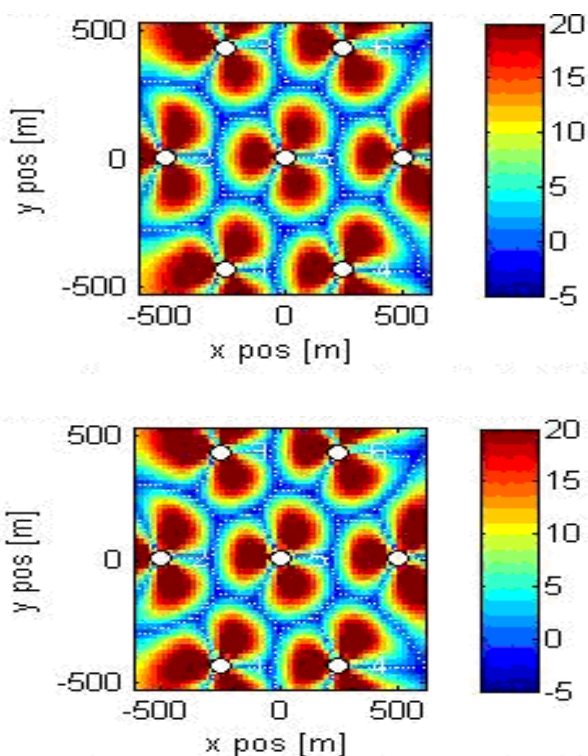

(a)
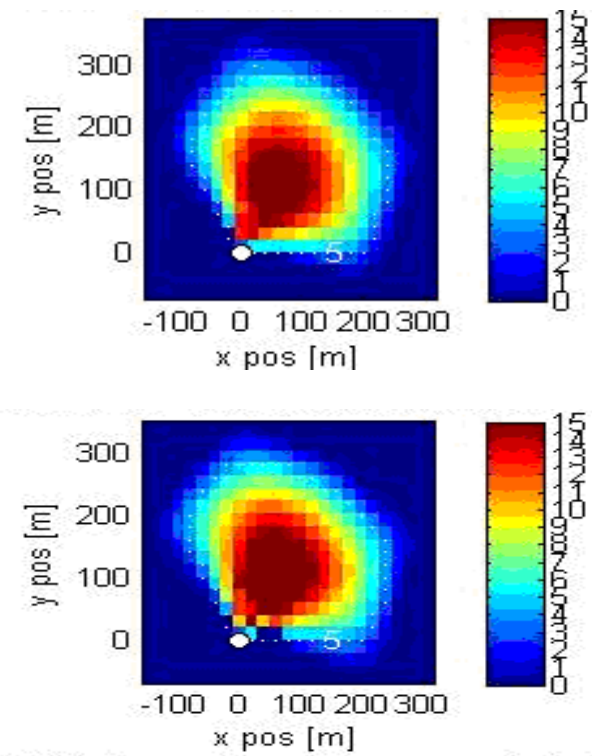

(b)
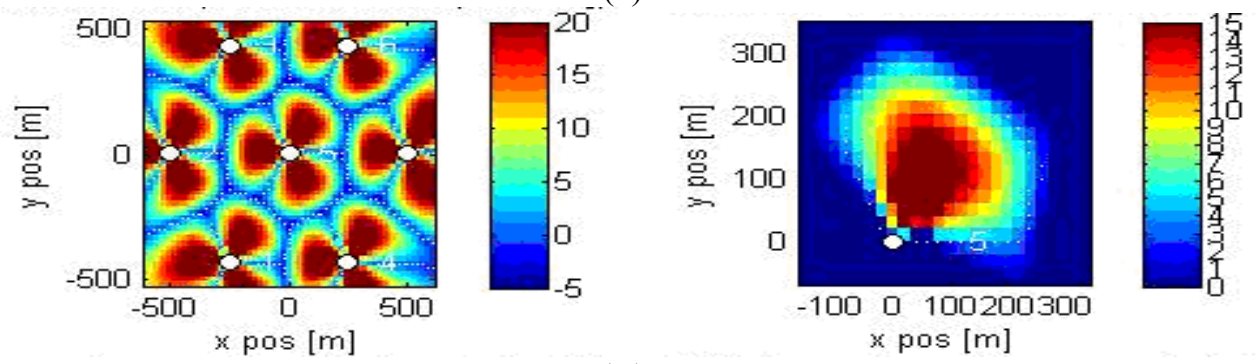

(c)

Figure 4: Macroscopic fading for antenna tilts of (a) $0^{\circ} \quad$ (b) $1^{\circ} \quad$ (c) $2^{\circ}$

Here the red region (denoting stronger signal level) increases with increase in the electrical tilt of the antenna at the base station. With a $2^{\circ}$ tilt the lobe of red color has maximum coverage in the area near to the base station as compared to that with $0^{\circ}$ and $1^{\circ}$, tilt angles. Hence the SINR is higher in this region and it decreases as we go away from the base station antenna. Also the cell edges experience less interference from neighboring cells base station because the signal strength reduces in the regions near the cell edge.

We conclude that tilting enables improvement in SINR in the region of interest and also help in interference management. A larger antenna height enables coverage at the cell edges. While tilting the large antenna ensures coverage in the desired areas nearer to the base station. Hence the variable traffic load of the cell can be handled as per the requirement. Edward Benner and et.al. have studied the effect of tilting on rms (root mean square) delay spreads and had proved that systems with larger down tilted antennas provided better performance as compared to systems with low down tilted antennas [17].

Tilting of antenna requires careful planning so as to avoid intra/inter cell interference and ensure that the null zones are in the scarce/low traffic areas only. Frequent modification of the tilt angle is possible by using either remote controlled tilted antennas or manual tilting of antennas by climbing on the antenna mast. Later method is more expensive. Planning tools like Atoll, ACP (Automatic Cell Planning) are used to decide the optimum elevation angle so as to ensure SINR improvements in the region of interest [18]. These optimum values of antenna heights and antenna tilts are then utilized for deployment of the network and verification of the simulated results is done by practically carrying out drive tests and calculating the coverage and C/I (carrier to interference ratio), values for determining the system performance. Practically, antenna heights of about $30 \mathrm{~m}$ and tilt angle of $7^{\circ}-8^{\circ}$ for $15 \mathrm{dBi}$ gain and $3.5^{\circ}$ to $4^{\circ}$ for $18 \mathrm{dBi}$ gain are found to provide better performance [19].

\section{Conclusion}

Antenna height and antenna tilt are critical parameters for network planning. Before deploying a network it is important to know the right values of these parameters so that proper coverage is obtained in the cell and desired SINR is maintained so as to ensure the optimum performance of the network. For the LTE systems in urban areas, antenna height of $25 \mathrm{~m}$ - 30m gives better SINR performance and appropriate electrical 
tilt improves the SINR in the dominance area of the cell. For the scenario considered for study, antenna height of $25 \mathrm{~m}$ and tilt of $2^{\circ}$ gives better SINR values.

\section{VI. future scope}

Impact of Antenna height and electrical tilt on SINR in urban and suburban areas for LTE advanced system deployments will be studied with LTE and LTE advanced system level simulators. Further, studies can be carried out to study the effect of antenna gain on SINR in LTE systems.

\section{References}

[1]. K.L. Blackard, M. J. Feuristein, T.S. Rappaprot and S. Seidel, Path loss and delay spread models as function of antenna height for microcellular system design, in 42nd IEEE Veh. Technol. Conf., Denver, Co, May 1992, pp. 333-337.

[2]. S. Kozono, Propagation characteristics in wideband mobile channels, in 4th Intl. Conf. on Wireless Communications, Calgary, AB, July 1992.

[3]. J.P. de Weck, P.Merik and R.W. Lorenz, Power delay profiles measured in mountainous terrain, in $38^{\text {th }}$ IEEE Veh. Technol. Conf., Philedelphia, PA, June 1988, pp. 105-111.

[4]. W. Mohr, Wideband propagation measurements of mobile radio channels in mountainous areas in the $1800 \mathrm{MHz}$ frequency range, in $43^{\text {rd }}$ IEEE Veh. Technol. Conf., Secaucus, NJ, May 1993, pp. 49-52.

[5]. M.J. Feuerstein, K. L. Blackard, T.S. Rappaport, S.Y. Seidel and H.H. Xia, Path loss, delay spread and outage models as function of antenna height for microcellular system design, IEEE Trans. Veh. Technol., Vol. 43, no. 3, PP. 487-497, Aug. 1994.

[6]. K. A. Akpado, O.S. Oguejiofor, C.O. Ezeagwu and A.U Okolibe, Investigating the Impacts of Base Station Antenna Height, Tilt and Transmitter Power on Network Coverage, Int'1. Journal of Engg., Science Invention, Vol. 2, issue 71, pp. 32-38, July, 2013.

[7]. F. Athley and M. Johansson, Impact of electrical and mechanical antenna tilt on LTE downlink system performance, Vehicular Technology Conference (VTC spring), IEEE $71^{\text {st }}$, Tapei, Taiwan, May 2010.

[8]. V. Wille et.al., Impact of antenna downtilting on network performance in GERAN systems, IEEE Conference, Lett., vol. 9, no. 7, pp. 454-462, Jul.2005.

[9]. I. Forkel, A. Kemper, R. Pabst and R. Hermans, The effect of electrical and mechanical antenna downtilting in UMTS networks, $3^{\text {rd }}$ Int'l Conference on 3G Mobile Communication Technologies, (Conf. Pub. No. 489), pp. 86-90, 2002.

[10]. O. yilmaz, S. Hamalainen, J. Hamalainen, Comparision of remote electrical and mechanical antenna downtilt performance for 3GPP LTE, Vehicular Technology Conference Fall (VTC-Fall), IEEE 70 ${ }^{\text {th }}$, Anchorage, USA, Sep. 2009.

[11]. M. Ismail, X. Xiang, and R. Mathar, Autonomous antenna tilt and power configuration based on CQI for LTE cellular networks, Tenth Int'l symposium on wireless communication systems, 2013, Verlag, Germany.

[12]. B. Partov, J. Douglas and R. Razavi, Utility Fair Optimization of antenna tilt angles in LTE networks, arXiv: 1310.1015v1 [cs.NI], October 2013.

[13]. K. Ghanem and H. Alradwan, The effects of tilting antennae on ping-pong handover in Inter eNBs handover, Int'l journal of research in wireless systems (IJRWS), vol. 1, issue 1, November 2012.

[14]. H. Hakim, H. Eckhardt and S. Valentin, Decoupling antenna height and tilt adaptation in large cellular networks, 8th International Symposium on Wireless Communication Systems (ISWCS), Page(s): $11-15$, 6-9 Nov. 2011,.

[15]. J. Niemela, T. Isotalo, J. Borkowski, and J. Lempiainen, Sensitivity of optimum downtilt angle for geographical traffic load distribution in WCDMA, Proc. IEEE Veh. Technol. Conf. (VTC-Fall), Sep. 2005.

[16]. LTE downlink system level simulator, Available online at: http://www.nt.tuwien.ac.at/research/mobile-communications/ltesimulators/.

[17]. E Benner and A. Sesay, Effects of antenna height, antenna gain and pattern downtilting for cellular mobile radio, IEEE transactions on vehicular technology, Vol. 45, no. 2, May 1996.

[18]. M. Alexandru and R. Urechiatu, LTE indoor radio coverage optimization study in modern city environments, review of air force academy, No. 2 (26), 2014

[19]. Leopedrini, What is Antenna Electrical and Mechanical Tilt (and How to use it), online: http://www.telecomhall.com/what-isantenna-electrical-and-mechanical-tilt-and-how-to-use-it.aspx, Thursday, October 13, 2011. 